Irfan OSMANOVIĆ, BA*

Teaching Assistant, University of Vitez

Associate, Law Firm "Sudžuka \& Co." Ltd.,

Ena KAZIĆ-CAKAR, PhD

Assistant Professor,

International University of Sarajevo
Original Scientific Article

UDK: 343.95:78.073

Recieved: 25 December 2020

Accepted: 26 March 2021

https://doi.org/10.47152/rkkp.59.3.1

\title{
MUSIC AS A FACTOR IN ETIOLOGY OF CRIME: CAN IT MAKE US ACCEPT THE UNACCEPTABLE?
}

With no intention to present the importance of music for our lives and for the culture, lesser than it truly has, authors are testing the role of music as a potential factor in etiology of crime. More specifically, they are trying to question whether the music lyrics whose content indicates acceptability of actions that are usually not acceptable, moreover that are criminal, might have an influence on individual so that person perpetrates criminal offence. After brief overview of criminological theories that correlate music and crime, authors will present qualitative study on lyrics of one of the most famous rap duos in Bosnia and Herzegovina, with the analysis of the text, and results of survey conducted among student population of Bosnia and Herzegovina, regarding the general and personal influence of the duo's music.

Keywords: etiology of crime, music, criminal offence, factor of crime.

* E-mail: irfan.osmanovic@s-law.ba

** E-mail: e.kazic12@gmail.com,ekazic@ius.edu.ba 


\section{Introduction}

Determining whether or not there is an empirical relationship between violent music lyrics and criminal behaviour is a complex endeavour given the many factors and forces that shape criminal behaviour on an individual level. We are all influenced on some level by our daily surroundings. Peer groups, TV shows, music, books, news media, personal experience, hobbies, education, habits, the community and culture in which we live, and the cultural artifacts that populate the culture make their way into our thinking and behaviour (Helfgott, 2008:13).

Media is one of the factors which has the strongest effect on our social life and behaviour. As a mean of communication, media has undergone significant developments which have made easier and cheaper access to information 24 hours a day and seven days a week possible. Such developments made knowledge about crime and criminality more accessible, both in quality and quantity. Nowadays, media is able to inform us about a criminal happening within minutes of the incident. Even though accessibility to such information can be highly beneficial for the society in general, there is always the risk that information will not be transmitted properly, fully or even truthfully. Thus, spread of wrong information, also known as "fake information", or even promoting socially undesirable events can negatively impact individuals and the society in general.

Discussions about whether media has a role in the increasing presence of violent crimes in our socio-cultural life are very common. Some argue that, the media whose basic aim is supposed to inform the public has become a tool for promotion of commercial products such as music and music videos - which can be seen as a result of the current capitalist approach. According to Sukru Nar (Sukru Nar, 2014: 57), the media of today has built its structure totally on profit, and it aims to increase its popularity rate in public opinion by means of showing violent crimes quite often. Under these circumstances, the media have become the determinant element at the point of accepting or rejecting a crime and deviant behaviour among the members of society. For example, media presents phenomenon such as corruption, abuse of power or prostitution, which previously provoked strong social reactions, as usual events. Also, songs and related artistic compositions often normalize degrading treatment and violence against women.

This paper aims to question correlation of one of the most influential media channels - music in perpetration of criminal offences. Few criminological theories will be tested in that direction. After given theoretical background, authors will present a case study of two contemporary rappers from Bosnia and Herzegovina - commonly recording their songs as duets - and the analysis of lyrics of their works. Additionally, brief research results on impact on their 
music on youth perspective on this will be given. In this paper descriptive and deductive research methods will be used, while case study, content analysis and questionnaire will be used as data collection methods. It is expected that the results of this research will rise the public awareness about the impact of certain music genres in the etiology of crime and may help in understanding the potential harmful consequences that music genres might have in some cases in society, together with other risk factors.

\section{Influence of Popular Culture on Crime and Criminal Behaviour}

The studies regarding the relation between popular culture and criminal behaviour demonstrate an increasing indifference in society towards such events (Sukru Nar, 2014: 59). According to Sukru Nar (Sukru Nar, 2014: 60), such result makes us to accept violence and crime, a result of violence, as an ordinary and even a necessary component of life. In accordance with this approach, the fact that media frequently emphasizes criminal offences and violence is a supporting factor in terms of creating an indifferent and irresponsible society and for directing individuals to committing criminal offences and engage in violence. By this way, media clearly deviates from its fundamental function which is to inform public and gradually becomes a crime-promoting tool that leads to social acceptance of perpetrators, their actions and consequences of such walks of life. Recent development and innovations enabled Media to penetrate all spheres of our lives and reshape our perception of events, especially those we are taught to perceive as unacceptable and forbidden. Also, Sukru Nar (Sukru Nar, 2014: 64) points out that "individual or groups of people can accept the realities of media world without questioning them and they can't realize exactly the difference between real world and artistic world".

American Psychiatric Association (American Psychiatric Association, 2014: 35 ), on the effects of media violence reports that 'over the last three decades, the one overriding finding in research on the mass media is that exposure to media portrayals of violence increases aggressive behaviour in children. In addition to increased aggression, countless studies have demonstrated that exposure to depictions of violence causes desensitization and creates a climate of fear."

\subsection{Our Daily Music}

Music is part of existence of human kind from its roots, since it is well known that from that time until now, that music is a media of expression of humans' 
feelings related to different situations in life. Music of different styles is heard upon birth of a child, within funerals, during celebrations, work, travel, fun. But, perceiving music solely as a media of transferring emotions would be incomplete perception of what it truly is.

Based on Merriam-Webster's Dictionary ${ }^{1}$ music is "the science or art of ordering tones or sounds in succession, in combination, and in temporal relationships to produce a composition having unity and continuity".

Cambridge Dictionary ${ }^{2}$ defines music as "a pattern of sounds made by musical instruments, voices, or computers, or a combination of these, intended to give pleasure to people listening to it". Britannica Encyclopedia offers definition of art that is the closest to perception about it by average person. According to Britannica Encyclopedia ${ }^{3}$, it is "art concerned with combining vocal or instrumental sounds for beauty of form or emotional expression, usually according to cultural standards of rhythm, melody, and, in most Western music, harmony”. Finally, another understanding is offered by many others, such is Hollman (Hollman, 2013: 20) who values "music as a form of expression".

No matter which one of these definitions we decide to embrace, fact is that music is present in our everyday actions and it can be said that it enriches our lives. Scientifically, its positive effects on brain and its development are recognized, so it is frequently used in pedagogy, psychology and in many other sciences as an adjunct method. According to Gardstrom (Gardstrom, 1999: 208), music reduces stress and it is favourable for health and in overall it is important for well-being.

Having in mind the importance and enriching effect of music to human kind, it is very sensitive to outline music as a potential ethio criminalis. Nevertheless, it is crucial to test what Gardstrom (Gardstrom, 1999: 208) calls "destructive effects of music", so that eventual other side of it can be corrected and in future can be excluded as ethio criminalis as such.

\subsubsection{Correlation of music and crime in criminological lenses}

Criminology, as a science about crime, offers various theories and conceptions which are trying to identify main criminal factors that might cause criminal offence. Few of these theories are involving music as one of those possible factors, but each of them from different point and argumentation.

1 Merriam-Webster's Dictionary, www.merriam-webster.com,

2 Cambridge Dictionary, https://dictionary.cambridge.org/dictionary/english/music

3 Britannica Encyclopedia, https://www.britannica.com/art/music 
One of the theories that indirectly correlates music and crime is Social learning theory. According to Adler et al. (Adler et al., 2018: 176) this theories' standing point is in the idea that "delinquent behaviour is learned through same psychological processes as any other behaviour". They add that "we learn behaviour in different ways: through observation, direct experience and differential reinforcement". So, how then music can be found as a possible cause of criminal offence. Main representative of this theory, Albert Bandura explains that people learn behaviour and aggression through behavioural modelling (Adler et al., 2018: 176). A child will learn its behaviour from role models it has: parents, teachers, or other peers they highly estimate. So, if a child idolizes popular singer and finds that person as a role model in the life, that persons' behaviour and message it sends through its songs will be of high importance to that child and might consequently accept it as a model of behaviour. Music played by those idols, whose lyrics approve violence of criminality any kind, encourages drugs consumption and incites crime, sends message that musician share those values and approve those actions, so youngsters learns that behaviour is good and desired, so consequently makes them to perpetrate those actions. In this context, Hollman (Hollman, 2013: 2) points out the importance of social environment for an individual and its future behaviour. According to her (Hollman, 2013: 2) the ,process of social behaviour is result of conditioning", so even when one action is being conducted, ,based on the positive or negative feedback from the social environment", that action will be understood as desirable or criminal.

Furthermore, Tropeano (Tropeano, 2006: 31) in her paper presents results of scientific research that tested the influence of violent music lyrics and videos on individuals' behaviour. In this psychological research there were three groups of participants: 11 individuals listening to violent music, 11 individuals in the control group and 11 individuals listening to non-violent music. The results showed that "watching the violent music video, containing violent lyrics, aggressive behaviour and degrading behaviours toward women did make an individual feel and react more violently with regards to response to questions about fictional scenarios" (Tropeano, 2006: 32). The conclusion was that "watching violent music videos does negatively affect behaviour" (Tropeano, 2006: 32). The same author refers to similar researches made by St. Lawrence and Joyner in 1991 and Johnson, Jackson and Getto in 1995, together with research of Anderson et al. from 2003, who proved that "exposure to media violence had a statistically significant association with aggression and violence among youth" (Tropeano, 2006: 31).

That brief explanation of social learning and importance of social environment for valorisation of conducted actions, brings us to contiguously related ideas of the Theory of subcultures. Based on ideas of Miller, this theory suggests 
that ,unique subculture might be built within social class or group“ (Adler et al., 2018: 125). Music may be a way of one subculture to represent their tradition, ideas and view on reality. It is being accepted and nourished like that, and messages that appear within it might not correspond to the ideas of other subcultures and might even be in conflict.

Sutherland's Theory of differential association might be correlated with our question about relation between music and crime, as well. This theory is based on the idea that if an ,individual's peers engage and support crime, the individual will develop favourable opinion on crime,, (Hollman, 2013: 5). This theory is one of concepts of interaction (Šeparović, 1981: 25), and it stipulates that association with individuals who cherish crime and distancing from positive, anti-criminal peers might make an individual to embrace criminal behaviour as the principal behaviour. If a music peer suggests through the music ideas about permitability of crime, logical consequence is that the fan will accept it as appropriate type of behaviour.

Hip hop, heavy metal and rap are mostly criticised in the scientific literature and many would say they are ,under attack“ (Gardstrom, 1999: 210). According to Steinmetz and Henderson, hip hop music ,emerged as a voice for a group previously limited in it possibilities" and they in practice create subculture. It is that what Gardstrom (Gardstrom, 1999: 210) calls inner-city expression of the youth subculture. Steinmetz and Henderson (Steinmetz, Henderson, 2016: 115) see hip hop as ,a vehicle to ascertain the community's perception about crime causation and motivation" and find that hip hop artists portray and explain crime as a result of ,retribution (47,58\%), environmental conditioning (24,19\%), strain $(17,74 \%)$, choice $(6,4 \%)$, social learning $(4,84 \%)$, oppression $(5,6 \%)$ and other $(4,8 \%)^{\text {“" }}$. Douglas Pond Cummings (Cummings, 2010: 516) states that hip hop critiques punishment being unfair and bias. Even though it tends to correct social issues, it can cause social issues and criminal behaviour, because, through that music, fan might protest existing justice system and by expressing dissatisfaction in different ways, consequently may get into criminal zone (physical attacks, gang violence, destruction of property within protests). When it comes to the heavy metal, according to Gardstrom (Gardstrom, 1999: 208), claims that it causes destructive and self-destructive behaviour usually fail on the basis of the freedom of speech.

\section{Rap Music and Criminality}

Dunbar (Dunbar, 2017: 177) notes that "rap music was created, in large part, as a response to social marginalization and police oppression, and it has had a 
contentious relationship with the legal system - perhaps more than any other music genre". However, we have to distinguish socially conscious rap music from problematic hip-hop music that focuses on violence, crime and "gaining riches" (Cummings, 2010: 523) which represents the majority of what is present on the music scene of today. As Cummings notes about hip-hop: "today it is all about the money and less about the passion behind the music. The more violent the lyrics, the more popular is the song." Unlike in contemporary hip-hop, references to crime and violence present in rap music are aimed at condemning that kind of behaviour and displaying those elements as socially disruptive instead of promoting them. While rap music, especially that from $20^{\text {th }}$ century, mostly emphasizes negative effects of crime and violence, modern hip-hop glorifies their consequences.

\subsection{Weitzer \& Kubrin Study: Rap Music and Misogyny}

According to Merriam-Webster Dictionary ${ }^{4}$ misogyny is defined as hatred of, aversion to, or prejudice against women. Even though it is not criminal in strict sense, misogyny, as reference highly present in modern hip-hop music, should be seen as socially undesirable phenomenon. As such, it should not have a place within popular lyrics due to its serious implications for perception of women and their social roles and general expectation.

In 2009, Weitzer and Kubrin (Weitzer, Kubrin, 2009: 24) conducted a research which examined the topic of misogyny in rap music. Particular focus was at the "gansta rap" albums published during the 1990s. As expected, the results of this research have clearly shown the reasonable concern about the misogynistic connotations. Out of 403 songs analysed, misogyny was recorded in $22 \%$ of cases.

Weitzer \& Kubrin study (Weitzer, Kubrin, 2009: 24) shows that sexual objectification comes in as the most frequent of all misogynistic themes (67\%) and "refers to the idea that women are only good for sex". Such lyrics promote women as exclusively sexual objects designed for male desires which should be expressly used and then discarded afterwards. Lyrics tend to generalize women stripping them off of their human identities and characteristics which go beyond their physical and sexual attributes. Meanwhile, lyrics often point out that men need to have many sexual partners in order to be successful in life. Weitzer \&

4 Merriam-Webster Dictionary, www.merriam-webster.com 
Table 1. Misogynistic Themes in Rap Songs (Source: Weitzer \& Kubrin, 2009)

\begin{tabular}{lc}
\hline Theme & Frequency in Songs (\%) \\
\hline Naming and shaming & 49 \\
Sexual objectification & 67 \\
Distrust of women & 47 \\
Legitimating violence & 18 \\
Prostitution and pimping & 20 \\
\hline
\end{tabular}

Note: Frequency in songs identified as misogynistic, not within the larger sample of rap songs (where $22 \%$ of the songs were categorized as misogynistic).

Kubrin Study (Weitzer, Kubrin, 2009: 27) explains how all of these actions are committed in strive peer validation and approval. A pressure is put on men to assert their masculinity by engaging in sexual intercourse with women easily and often. This leads to a conclusion that, aside from misogyny, the ideal of hypermasculinity is highly present in rap music. Such ideals might negatively influence the development of young males who often look up to rap artists and see them as their role models. The research found that "Male sexual bravado and hyper-sexuality was present in $58 \%$ of the misogynistic songs."

\subsection{Rap Music and Violence}

According to Richardson and Scott (Richardson, Scott, 2002: 226), rap music gained notoriety due to its misogynous themes, hyper-materialistic striving, violent lyrics, and the behaviour and attitude of majority of its artists. However, antisocial behaviours, or activities considered reprobate by predominant cultural norms (e.g., killing police officers or participating in street fights) are symptoms of far more complex and multifaceted issues than commonly recognized. Risk factors such as poverty, drug and alcohol abuse, gang participation, and pervasive violence in all forms of media have been blamed for the 10 children and teens that die every day in the United States. Also, many rappers use threat of rape and sexual assault as a response to being turned down by women, either sexually or romantically. In some instances, rap lyrics even incite a feeling of pride and honour in hurting women through differing sexual acts which points once again to the misogynistic character of such media content.

On contrary, some researchers have argued that society in some ways, needs rap music- no matter how seemingly misogynous, hyper-materialistic and hedonistic- to illustrate cultural norms of the urban poor (Richardson, Scott, 2002: 230). 


\subsection{Rap Music and Drug Use}

To anyone who has been even mildly exposed to rap music, and/or the accompanying music videos, it is clear that they are replete with references to drugs and drug use. In addition to "common" marijuana-related references, there's a plethora of allusions to other drugs - also known as "hard drugs" such as cocaine, heroin, speed, etc. - and their beneficial effects on human's performance in life, business and sexual intercourse. Jhawer (Jhawer, 2017: 12) points out that it seems like the more drug references the rappers insert in their lyrics, the more fame they will attain. Somehow, alluding to drugs and their effects has become a guaranteed path to success in the world of contemporary rap and hip-hop music.

According to Jhawer (Jhawer, 2017: 12), the deepest-rooted issue arises from when popular cultures glorifies drug indulgence for others, to the point where individuals start doing drugs and referencing it for the sake of "having done so", improving "street creed" or for the purposes of simply being perceived as "cool".

Robert Preidt concludes that rap music is glamorizing drug use, which is clearly confirmed by a study by researchers at the University of California, Berkeley (Preidt, 2019), which found a six-fold increase in drug references in songs in the last 20 years. According to this study: "Positive portrayals of drug use have increased over time and there was an increase in songs featuring positive attitudes toward drugs and the consequences of drug use, and an increase in references of drug use to signify glamour, wealth and sociability. In addition to this conclusion, there was a significant change in the types of drugs mentioned in rap songs."

These developments need to be perceived as alarming since rap artists have become role models for youth all across the world. This is particularly true for urban areas and developing societies where the youth is experiencing significant economic hardships and social challenges, and is, thus, more inclined to resort to criminality more often even without the encouragement from rap music.

\section{Crime and Criminal Behaviour in Lyrics of $R$ and $P$}

As previously noted, music and content showcased in its lyrics can have a tremendous impact on our lives - both positive and negative. Constant increase in the crimes and violence references in the rap lyrics is clearly a negative one, and should be raising a particular concern for the perception of crime and attitude towards it of many followers of rap music - especially the youngest parts of population. Lyrics of two rap performers trending in Bosnia and Herzegovina and rest of the Balkans, $\mathrm{R}$ and $\mathrm{P}$, are replete with alarming references to drugs, crimes and violence. 


\subsection{Elements of Crime and Criminal Behaviour in Lyrics}

In order to empirically demonstrate the high presence of such references on contemporary music scene in Bosnia and Herzegovina, 20 songs $^{5}$ performed jointly by $\mathrm{R}^{6}$ and $\mathrm{P}^{7}$ were analyzed. Analysis was focused on detecting misogynistic and derogatory sexist vulgarism, swear words, and references to use of violence, drugs and showcasing crime as a vehicle of acquiring wealth, success and female attention.

\begin{tabular}{|l|c|c|}
\hline \multicolumn{1}{|c|}{ Theme } & Number of times mentioned & \% \\
\hline a) Misogyny & $14 / 20$ & $70 \%$ \\
\hline b) Violence & $12 / 20$ & $60 \%$ \\
\hline c) Drugs & $11 / 20$ & $55 \%$ \\
\hline d) Sexual acts & $10 / 20$ & $50 \%$ \\
\hline e) Crime & $10 / 20$ & $50 \%$ \\
\hline f) Swear words and curses & $14 / 20$ & $70 \%$ \\
\hline
\end{tabular}

Examination of R and P's lyrics in the table above showcases that there is a justified reason for concern about their listeners' attitude towards crime. Great majority of their songs and lyrics thereof contain problematic representation of misogyny, glorification of violence, drugs and crime and commonly refer to sexual interactions in degrading manner followed by swear words.

Concerning 70 percent of the examined lyrics contain derogation references to women - most commonly attaching women to prostitution and labeling them as purely sexual objects designed for male satisfaction (misogyny).

Mentions of violence, in terms of glorification and promotion, were present in 60 percent of the analyzed songs - which is a particularly relevant information

5 The sources (songs) are not named in order not to correlate them with singers, as their identity is anonymized in order not to affect their personal reputation in any way. They were selected as examples from the referred music genre and are among the most popular interpretators with hundred million of views on social media in Bosnia and Herzegovina. The example used here as an illustration of the author's opinion, is for scientific purposes only, and is not intended to personally or professionally affect their reputation by any means.

$6 \mathrm{R}$ is a Bosnian rapper, songwriter and producer. He is best known for collaborating with another Bosnian rapper, $P$ and singer $M$. Use of R's real name was purposely avoided in order not to affect their personal reputation in any way.

$7 \quad \mathrm{P}$ is a Bosnian rapper, songwriter, producer and entrepreneur. Use of P's real name was purposely avoided in order not to affect their personal reputation in any way. 
for the Adler's Social learning theory which can be the basis of connecting the violence in music lyrics with the occurrence of violent criminal offences in real life.

Other references, such as drugs, sex, general crime and common swear words were also detected in a great number of lyrics - ranging between 50 and 70 percent. Another point worth noting is the fact that the examined songs are very popular on YouTube and count the number of views in high millions, even up to 100 million views. This leads us to the conclusion that such artwork is successfully and routinely reaching millions of youngsters in Bosnia and Herzegovina and globally, and is (re)shaping their perception of crime and criminality.

\subsection{Student Survey on Music Works and Lifestyle of $R$ and $P$}

In order to examine the public opinion about this important topic, 30 survey subjects, random students from Faculty of Law and Faculty of Social Sciences were asked about this topic. Survey pool was limited to 30 participants because those students were enrolled in classes which touched upon the possible connections between media and criminality (i.e. Criminology course). Students were between the age of 18 and 23, with 19 female and 11 male participants in the survey. They were asked the following questions about the quality of music works R and P:

- Are you familiar with works of [R's real name] and [P's real name]?

- Are you familiar with works of R and P?

- Do you enjoy works of $\mathrm{R}$ and $\mathrm{P}$ ?

- Do you think that works of $\mathrm{R}$ and $\mathrm{P}$ are promoting wrong values, such as drug use, misogyny, violence and crime?

- Do you think that works of R and P negatively influence the youngsters who are listening to such music?

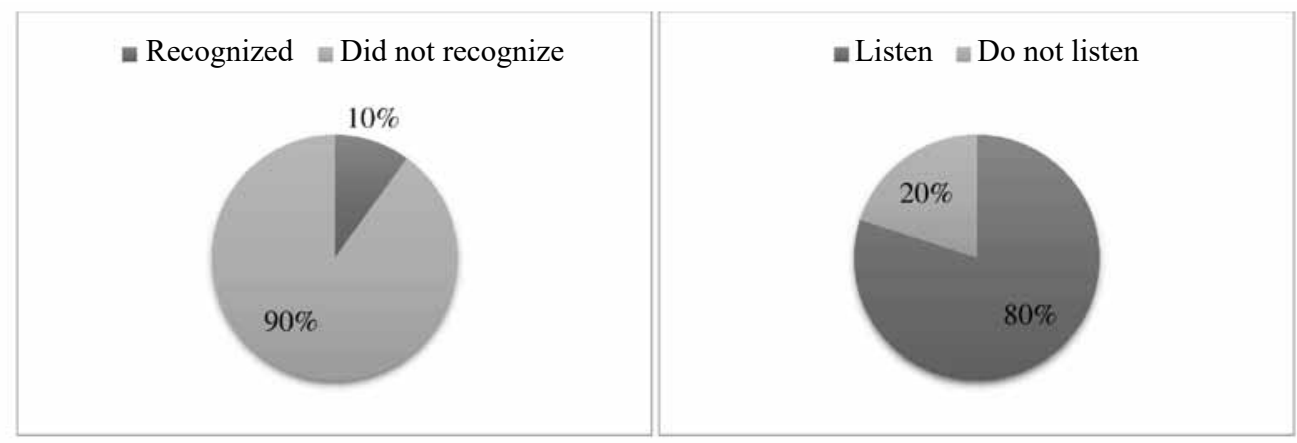

Graph 1 (left): $90 \%$ of students did not recognize R and $\mathrm{P}$ when presented only with their real names

Graph 2 (right): 80\% of students confirmed that they often listen and enjoy R and P's music. 
Even though all 30 students said they were familiar with R's and P's music, only three, or $10 \%$ of the survey subjects, recognized the artists once presented with their real names instead of the "stage names" they use to sign and advertise their songs.

24 students confirmed that they often listen and enjoy their music. However, 23 of them were able to point out the problematic elements in the lyrics of the music they listen to and have confirmed that such lyrics actively promote values they see as wrong, such as drug use, misogyny, violence and crime. Survey demonstrated that 28 out of 30 students think that works of these artists negatively influence their listeners and followers, especially children, teenagers and young adults.

- Can point out problematic elements

w Cannot point out problematic elements

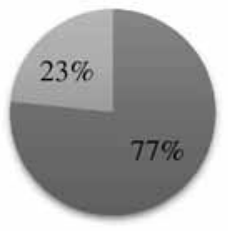

- Think that such music negatively influences listeners

= Do not think that such music has negative effects

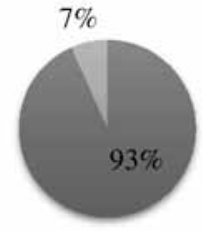

Graph 3 (left): $76 \%$ student were able to point out problematic elements - references to crime, violence, drug use and misogyny - in R and P's lyrics

Graph 4 (right) $93 \%$ of students consider such lyrics to have negative influence on their listeners, especially the younger population.

Also, survey subjects have generally agreed on the notion that exposure to such music could contribute to one's acceptance of crime and criminal deviancy and acceptable - and even desirable - behaviour.

\section{Discussion}

Music has been influencing human life and behaviour for hundreds, even thousands of years. Generally speaking, that influence can be seen as positive for an individual and the society in general, with enriching artistic effects. However, as previously demonstrated music has changed and is still changing by becoming less of a work of art and more of a tool of social influence. Seeing that new purpose of producing and recording music, one would righteously be concerned about plethora of negative ways such tool could be used. It is obvious that R and 
P's music, especially their lyrics and music videos, are being used exactly in order to spread and promote their values, lifestyles and vocabulary which can directly be correlated with Adler's theory of Social learning. Listeners, especially those young ones, listen to songs and watch music videos and they learn about the displayed delinquent behaviour just as they learn about sports, history or any other human action. Such listeners see those performers as someone to look up to - they see them as their role models and they even idolize them. Eventually, as Albert Bandura (Adler et al., 2018: 176) noted, music played by those idols, whose lyrics approve violence or criminality of any kind, encourages drug consumption and incites crime, sends message that musician - a role model - shares those values and approves of those actions, so youngsters learn that behaviour is good and socially desired, so consequently makes them to perpetrate those very actions. Also, it is no longer a rare phenomenon that somebody actively consumes such music. Today, majority of population belonging to a certain age group consume music and music videos filled with drugs, crimes and violence which leads us to Sutherland's Theory of differential association. The theory states that if peers of an individual also engage and support such music, he or she will also develop a favourable opinion. This theory then explains why behaviour displayed in the observed content is becoming socially acceptable, and even desirable, within certain groups and why is it so easily absorbed in their patterns of behaviour.

It is true that not every - probably not even the majority of listeners to such music works decides to replicate the actions and criminal offences displayed in that music, but potential reproduction is not the only hazard. Actually, it can be argued that not reacting to situations displayed in the music lyrics and videos once they happen in real life is a consequence of exposure to that content. For example, if a person who is constantly exposed to music whose lyrics do not condemn drug consumption but promotes it instead, he or she will not have a negative reaction once he or she encounters a situation involving drug consumption in real life and might even be eager to take part because his or her favourite rap artists does the same and is enjoying it. Similarly, to lack of condemning reaction - exposure to violent and crime-promoting music can lead to a stronger and more violent reaction in real life. Thus, Tropeano (Tropeano, 2006: 31) presented that 'watching the violent music video, containing violent lyrics, aggressive behaviour and degrading behaviours toward women did make an individual feel and react more violently with regard to response to question about fictional scenarios."

Therefore, in order to minimize the risk of crime-filled music and music videos influencing our youth, there needs to be a secure mechanism which would discourage them from consummating such materials. Music should be categorized similarly to movies and TV shows and played on TV and radio stations in late 
hours instead of being constantly present. Networks such as YouTube, which is the main source and spreading engine of music today, should stop recommending such videos and showing them as trending to their youngest users - unless they specifically type the artists name or song title into the search engine, it should not be popping up to children and teenagers. Most importantly, youngsters need to be educated about this issue in order not to blindly follow riches and the fame of those who call themselves singers and music artists today.

\section{Conclusion}

Various theories presented in the paper confirm potential correlation between music and violent/criminal behaviour. In 2020, the importance of media for directing social life and human behaviour is uncontested. This is especially true when seen from the standpoint observing the rapid developments in media making it easier and cheaper to access songs, videos and other related art creations from any point around the globe. Media is no longer only used for sharing useful and valuable information and content, but has become a profit-oriented structure without a moral compass which would isolate potentially hazardous media content. By failing to do this, media deviates from its fundamental function and is gradually becoming a tool for promotion of crime.

As an integral part of media, music has been particularly successful in communicating these ill-values causing "destructive effects of music" (Gardstrom, 1999: 208). After examining R's and P's songs, it is clear that their lyrics are abundant with socially "destructive elements" which can influence youngsters to copy those models of behaviour in their own lives. In other words, listening to music whose lyrics approve violence or criminality of any kind, just as scientifically proven, might encourage drug consumption and promote illegal activities as good and might incline the listeners to reproduce what they listen to in real world. That is the reason why the authors are indicating necessity of increased supervision (over the day) in playing critical music genres, especially through the media easily accessible to minors, just as the same supervision exists in movies display.

\section{References}

- Adler, F. et al. (2018) Criminology. USA: McGraw Hill Education.

- American Psychiatric Association. (2014) Report on the effects of media, pp. 34-41. Available at: https://stars.library.ucf.edu/cgi/viewcontent.cgi?article= $2683 \&$ context $=$ honorstheses1990-2015, accessed on 12.06.2020. 
- Cummings, A. (2010) Thug Life: Hip-Hop's Curious Relationship with Criminal Justice, Santa Clara L. Rev. 515. Available at: http://digitalcommons.law. scu.edu/lawreview/vol50/iss2/5, accessed on 25.06.2020.

- Dunbar, A. (2017) Rap on Trial: Do violent lyrics prove a crime?. Center on Media and Justice at John Jay College, pp. 174-188. Available at: https:// thecrimereport.org/2017/08/07/rap-on-trial-do-violent-lyrics-prove-a-crime/, accessed on 25.06.2020.

- Gardstrom, S. (1999) Music exposure and criminal behavior: Perceptions of juvenile offenders. Journal of Music Therapy, 36(3), pp. 209-220.

- Helfgott, J. (2008) The influence of technology, media and popular culture on criminal behavior, pp. 13-17. Available at: https://www.sagepub.com/sites/ default/files/upm-binaries/19507_Chapter_10.pdf, accessed on 02.05.2020.

- Hollman, A. (2013) Criminological Theory as Represented in Music Lyrics. Papers \& Publications: Interdisciplinary Journal of Undergraduate Research, 2 , Article 8. Available at: http://digitalcommons.northg, accessed on 11.06.2020.

- Jhawer, S. (2017) Why glorify drugs in hip-hop. The Stanford Daily. Available at: https://www.stanforddaily.com/2017/11/23/why-glorify-drugs-in-hiphop/, accessed on 13.11.2019.

- Preidt, R. (2019) Rap Music Glorifying Drug Use. ABC News. www.abc.com, accessed on 03.11.2019

- Richardson, J., and Scott, K. (2002) Rap Music and Its Violent Progeny. pp. 217-236. Available at: https://www.researchgate.net/publication/271778578 Rap_Music_and_Its_Violent_Progeny_America's_Culture_of_Violence_in_ Context, accessed on 26.06.2020.

- Šeparović, Z. (1981) Kriminologija i socijalna patologija (Criminology and social pathology). Zagreb: Pravni fakultet

- Steinmetz, K. F. and Henderson, H. (2016) Hip hop's Criminological Thought: a content analysis. Journal of Criminal Justice and Popular Culture, 18(1), pp. 114-125.

- Sukru Nar, M. (2014) The effect of Media as a Tool of Popular Culture on Crime. Journal of Studies in Social Sciences, 9(1), pp. 57-68.

- Tropeano, E. (2006) Does Rap or Rock Music provoke criminal behavior. Journal for Undergraduate Psychological Reasearch, vol. 1. Available at: https://www.scribd.com/document/103201399/Journal-of-UndergraduatePsychological-Research-2006-Vol-1-Does-Rap-or-Rock-Music-ProvokeViolent-Behavior-Eliana-Tropeano, accessed on 12.06.2020.

- Weitzer, R. \& Kubrin, C. (2009) Misogyny in Rap Music a Content Analysis of Prevalence and Meanings, Men and Masculinities, pp. 23-45. Available at: https:// journals.sagepub.com/doi/10.1177/1097184X08327696, accessed on: 10.06.2020. 
- Analysed songs are annonymized for purposes of not revealing the identity of singers.

\section{Online Sources}

- Preit, R. Rap Music Glorifying Drug Use, https://abcnews.go.com/Health/ Healthday/story?id=4569665\&page=1, accessed on 20.06.2020.

- Yang, S. New study finds glamorization of drugs in rap music jumped dramatically over two decades, https://www.berkeley.edu/news/media/releases/ 2008/04/01_rapmusic.shtml, accessed on 20.06.2020.

- Music. https://www.merriam-webster.com/dictionary/music, accessed on: 25.06.2020.

- Music. https://dictionary.cambridge.org/dictionary/english/music, accessed on 25.06.2020.

- Music. https://www.britannica.com/art/music, accessed on 10.06.2020. 